\title{
Combined thermal analysis of fluid plasticizers
}

\author{
Chukwuemeka L. Ihemaguba $\cdot$ Kálmán Marossy ${ }^{1,2} \mathbb{0}$
}

Received: 27 February 2020 / Accepted: 28 September 2020 / Published online: 18 October 2020

(c) The Author(s) 2020

\begin{abstract}
The paper deals with the study of plasticizers using different thermal methods. The literature data on the melting points of plasticizers proved uncertain; we intended to gather the data by other methods, differential scanning calorimetry (DSC), dynamic mechanical analysis (DMA) and thermally stimulated discharge (TSD). Results of ten plasticizers are demonstrated. During this work, we found that most of plasticizers have no well-defined melting point, and the solidification of plasticizer is similar to the glass transition of polymers. Only the di-n-butyl-phthalate showed regular crystallization. Thermally stimulated discharge current (TSD) method revealed that these compounds have several transitions -dispersion ranges assigned to different molecular motions.
\end{abstract}

Keywords Plasticizers · DSC · Dynamic mechanical analysis (DMA) · Thermally stimulated discharge (TSD)

\section{Introduction}

Melting point is an important property of a pure compound. This value is usually imparted in technical data sheets of plasticizers but without describing the method used. We intended to check the melting points by DSC.

The behavior of polymers is determined by relaxation processes; therefore, investigation and understanding these processes are essential. Reverse behavior of polymers makes possible the determination of these processes.

Even in homopolymers of simple structure, different relaxation processes running simultaneously make the analysis of experimental results difficult, for example, $\alpha$ relaxation (glass transition) assigned to main-chain segmental motion, the $\beta$ relaxation assigned to side-chain motion and further short-distance conformational motions. The picture is much more complicated if the material is complex, e.g., a copolymer, a polymer blend or plasticized one. The components might influence each other's mobility.

These processes can be investigated in mechanical field: thermo-mechanical analysis (TMA), dynamic mechanical analysis (DMA), thermally stimulated creep (TSC); in

Kálmán Marossy

polkal01@uni-miskolc.hu

1 University of Miskolc, 3515 Miskolc Egyetemváros, Hungary

2 Borsodchem Zrt, 3700 Kazincbarcika, Bolyai tér 1, Hungary electric field: dielectric thermal analysis (DETA), thermally stimulated discharge (TSD); and by thermal properties: differential scanning calorimetry (DSC). Tseretely [1] tested gelatins by DSC and stated glass transitions can be found in gelatins.

For testing liquid substances, DSC is generally used but DMA and TSD are seldom applied. Low molecular mass glassy solids and liquids like phenyl-salicylate, maltitol and glycerol were investigated by TSD [2], and relaxation processes were resolved by thermal sampling method. Rapeseed oil was tested by AC dielectric method [3] from $10 \mathrm{MHz}$ to $3 \mathrm{GHZ}$. Even $10 \mathrm{~Hz}$ is 4 to 5 orders of magnitude higher frequency than the effective frequency of TSD. [4]

The effect of plasticizers on the properties of polymers is a well-researched area. The plasticizers are also tested for the most important properties, e.g., volatility, compatibility, thermal- and oxidative stability, etc. However, we found that the published melting points are unreliable therefore cannot be used for predicting properties of plasticized polymer.

\section{Experimental}

\section{Materials}

All plasticizers tested were technical quality products, the DEHP high-purity medical grade. The list of plasticizers is given in Table 1. For TSD measurements, $60 \mathrm{gm}^{-2}$ 
Table 1 List of tested plasticizers and their published melting points

\begin{tabular}{lllll}
\hline Group & Plasticizer & Acronym & CAS & Published melting point(s) $/^{\circ} \mathrm{C}$ \\
\hline Phthalates & Di-n-butyl phthalate & DBP & $84-74-2$ & $-35[7-9]$ \\
& Di(2-ethylhexyl) phthalate & DEHP & $117-81-7$ & $-50[10],-72^{\mathrm{a}}[9]$ \\
& Di-isononyl phthalate & DINP & $28553-12-0$ & $-54[9,11]$ \\
& Diisodecyl phthalate & DIDP & $26761-40-0$ & $-45[12]$ \\
& Diundecyl phthalate & DUP & $3648-20-2$ & $-2[13],-65.8[17]$ \\
& Di-iso-tridecyl phthalate & DTDP & $119-06-2$ & $-37\left(-34.6^{\circ} \mathrm{F}\right)[14]$ \\
Adipates & Di(2-ethylhexyl) adipate & DOA & $103-23-1$ & $-67.8[9]$ \\
& Diisocecyl adipate & DIDA & $27178-16-1$ & $-71[8]-60[9]$ \\
Cycloaliphatics & Di(2-ethylhexyl) cyclohexanoate & DEHCH & $84731-70-4$ & $-40.7[15]$ \\
& Di-isononyl cyclohexanoate & DINCH & $166412-78-8$ & $-54^{\mathrm{b}}[16]$ \\
\hline
\end{tabular}

${ }^{\mathrm{a}}$ Glass transition temperature

${ }^{\mathrm{b}}$ Pour point

borosilicate glass fiber filter of $0.2 \mathrm{~mm}$ thickness and $2.6 \mu \mathrm{m}$ nominal pore size was used as scaffold material. Its pore volume is $87 \pm 2 \%$. Figure 1 shows the SEM image of the filter.

For DMA tests, $70 \mathrm{gm}^{-2}$ cellulose-based standard filter paper of $0.13 \mathrm{~mm}$ thickness was used as scaffold. Its pore volume is $60 \pm 5 \%$.

\section{Instruments and test methods}

For DSC measurements, a Mettler Toledo DSC 823e instrument was used with about $10 \mathrm{mg}$ sample in a standard $40 \mu \mathrm{l}$ aluminum crucible. The tests were carried out in the temperature range of -120 to $20^{\circ} \mathrm{C}$ with liquid nitrogen cooling using $10{ }^{\circ} \mathrm{C} \mathrm{min}{ }^{-1}$ heating rate. Heat flow was plotted by the standard software of the instrument then redrawn.
Dynamic mechanical measurements were carried out with Rheometric Scientific DMTA MK-III instrument in dual cantilever mode at $1 \mathrm{~Hz}$ frequency and $64 \mu \mathrm{m}$ peakto-peak amplitude. Heating rate was $2{ }^{\circ} \mathrm{C} \mathrm{min}^{-1}$. The specimens were paper filter strips soaked with the plasticizer to be tested. The accurate modulus cannot be calculated, but the mechanical loss factor $(\operatorname{tg} \delta)$ is correct.

Setaram TSCII Instrument was used for the TSD measurements with a cell supplied with the instrument as demonstrated in Fig. 2. Borosilicate glass filter disks of $7 \mathrm{~mm}$ diameter were soaked with the plasticizer and put into the standard cell. The mass of the glass filter is $2.3 \mathrm{mg}$ saturated with about 8 to $10 \mathrm{mg}$ plasticizer.

Cooling and heating rate was $5{ }^{\circ} \mathrm{C} \mathrm{min}^{-1}$; the heat transfer medium was helium gas. All depolarization curves were
Fig. 1 SEM image of borosilicate filter used as scaffold material for TSD
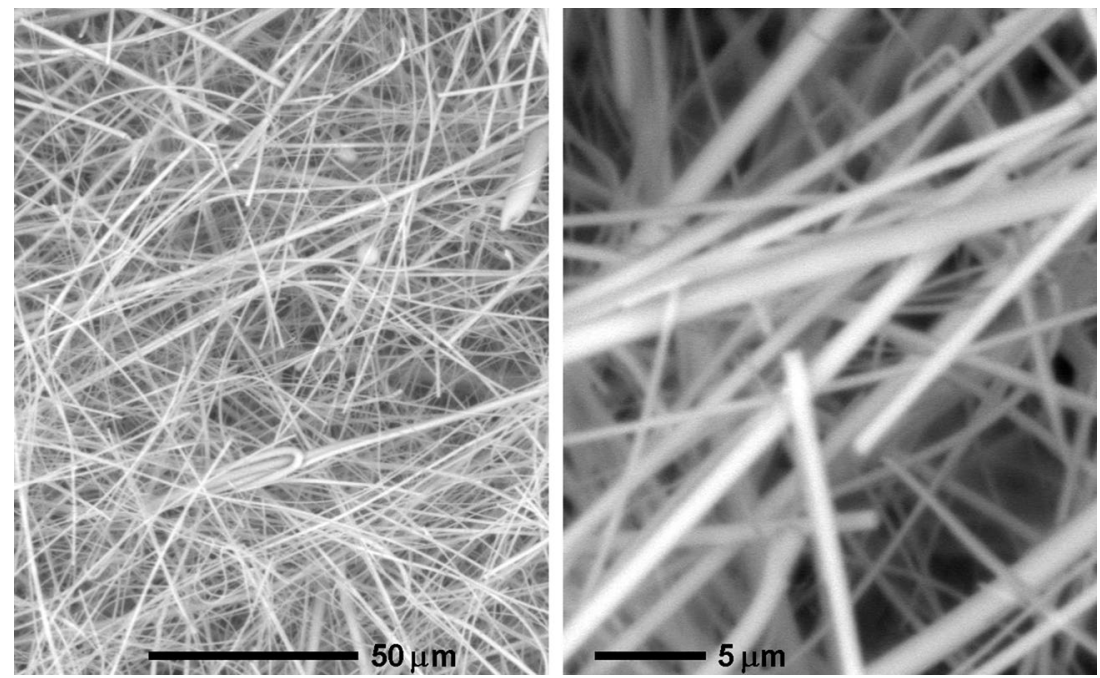


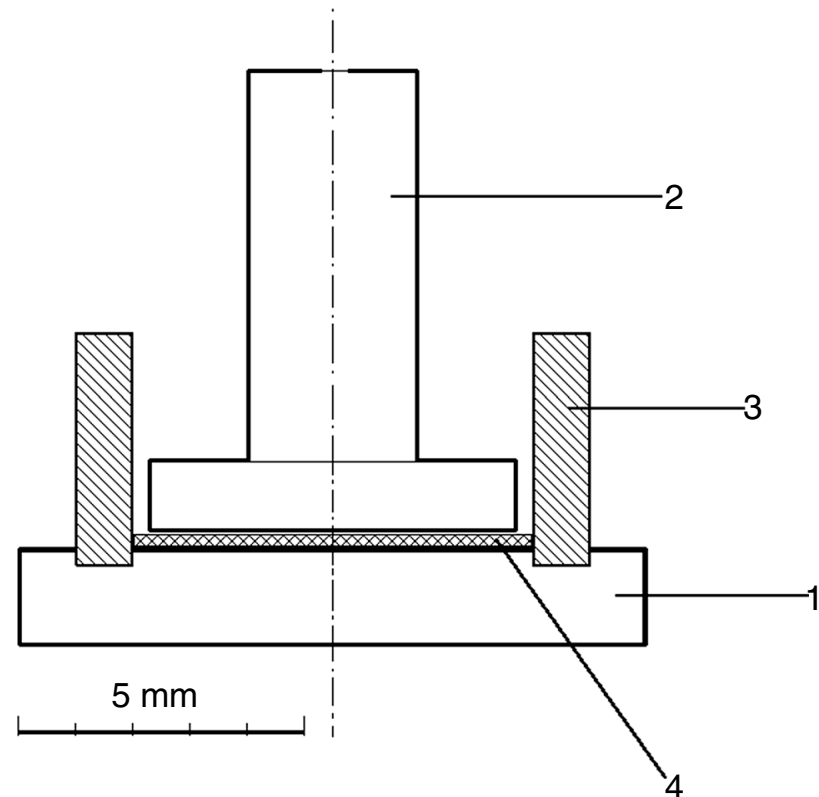

Fig. 2 Arrangement of TSD sample holder for fluids. 1 base (ground electrode); 2 upper electrode; 3 PTFE ring; 4 sample (borosilicate filter and plasticizer)

normalized to $30 \mathrm{~cm}^{2}$ area and $1 \mathrm{kVmm}^{-1}$ electric field. The details of the test and the instrument are described in [5].

\section{Results}

\section{Differential scanning calorimetry (DSC)}

The DSC curves of the plasticizers tested are shown in Fig. 3. The individual curves are shifted; relative scale is given on the left side. The low temperature peaks appear melting but these have been evaluated as glass transitions. These parts of the curves cannot be considered as melting peaks, because the integrals are less by more than one order of magnitude than of a melting process. Temperatures are summarized in Table 2 column DSC (1). Only two curves contain typical melting peak: the DBP and the DUP. Melting of DBP occurs at much higher temperature $\left(-8.6^{\circ} \mathrm{C}\right)$ than the published value $\left(-35^{\circ} \mathrm{C}\right)$. Interestingly, no other process can be observed below the melting temperature.

In case of DUP, the melting character at $-60{ }^{\circ} \mathrm{C}$ and $-15^{\circ} \mathrm{C}$ is questionable. The sharp endothermic peak with $0{ }^{\circ} \mathrm{C}$ onset is probably originated from small moisture content.

\section{Dynamic mechanical analysis (DMA)}

Dynamic mechanical analysis of fluids is quite strange. The filter paper either alone or filled with a fluid needs very low

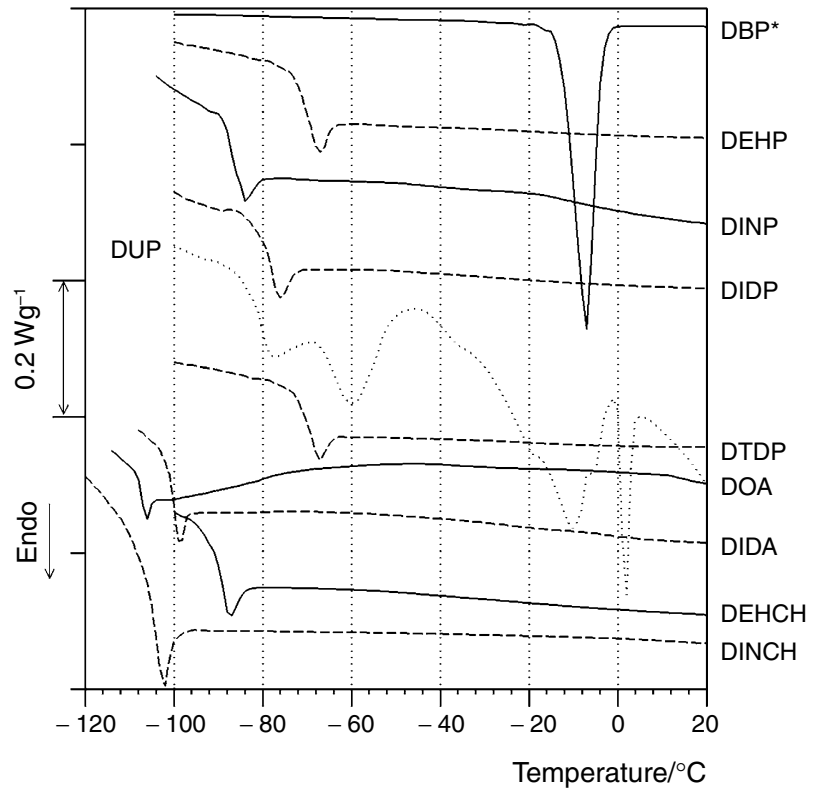

Fig. 3 DSC curves of plasticizers. * For DPB the scale bar is $2 \mathrm{Wg}^{-1}$

bending force. If the fluid is solidified, it behaves itself like a plastic film. Geometrical data are uncertain, but the relative error is the same both for E' and E"; the calculated mechanical loss factor $(\operatorname{tg} \delta)$ is accurate. Similarly to DSC results, the DMA tg $\delta$ curves are also plotted in one graph, as shown in Fig. 4. The $\operatorname{tg} \delta$ peaks are broad like that of a glass transition of a polymer. In some cases (DINP, DEHCH), multiple transitions can be supposed but resolving of these processes seems hopeless. Temperatures for $\operatorname{tg} \delta_{\max }$ are summarized in Table 2.

In case of DBP, the melting process found by DSC cannot be observed in $\operatorname{tg} \delta$ curves. There is no explanation at the moment.

\section{Thermally stimulated discharge (TSD)}

The saturated scaffold method was used. First the borosilicate filter was tested in order to determine any disturbing transitions. The depolarization curve of the filter is shown in Fig. 5 using logarithmic current scale. At low temperature, until $0{ }^{\circ} \mathrm{C}$ the polarization of the glass fiber is negligible.

Depolarization curves are complex and contain a number of transitions. Although all depolarization curves were resolved, demonstrating all results is not possible in this paper. Depolarization curves of plasticizers tested contain a very low temperature transition (TSD low) and a higher one (TSD high) in Table 2. Depolarization curve of DIDP is shown in Fig. 6 in solid line. Resolved transitions are plotted in different dashed lines. Low temperature $(-120$ to $-50{ }^{\circ} \mathrm{C}$ ) and higher $\left(-50\right.$ to $0{ }^{\circ} \mathrm{C}$ ) peak positions are given in Table 2. 
Table 2 Thermal analysis results on plasticizers tested

\begin{tabular}{lllrllc}
\hline Plasticizers & & $\begin{array}{l}\text { Carbon number } \\
\text { of alkyl group }\end{array}$ & DSC $/{ }^{\circ} \mathrm{C}$ & DMA $/{ }^{\circ} \mathrm{C}$ & TSD 1 high $/{ }^{\circ} \mathrm{C}$ & TSD 2 low $/{ }^{\circ} \mathrm{C}$ \\
\hline Phthalates & DBP & 4 & $-8.6^{\mathrm{a}}$ & -82.9 & -58.6 & -90.8 \\
& DEHP & 8 & -85.3 & -76.0 & -54.5 & -81.8 \\
& DINP & 9 & -82.7 & -72.8 & -47.1 & -83.1 \\
& DIDP & 10 & -85.7 & -63.7 & -38.8 & -76.0 \\
& DUP & 11 & -83.2 & -68.9 & -52.0 & -79.4 \\
Adipates & DTDP & 13 & -69.9 & -58.0 & -22.1 & -68.0 \\
& DOA & 8 & -109.0 & -97.2 & -38.8 & -104.7 \\
Cycloaliphatics & DEHCH & 8 & -100.9 & -83.2 & -51.6 & -96.8 \\
& DIDA & 10 & -96.7 & -90.7 & -31.5 & -92.0 \\
& DINCH & 9 & -87.1 & -76.1 & -26.8 & -86.0 \\
\hline
\end{tabular}

${ }^{a}$ Melting

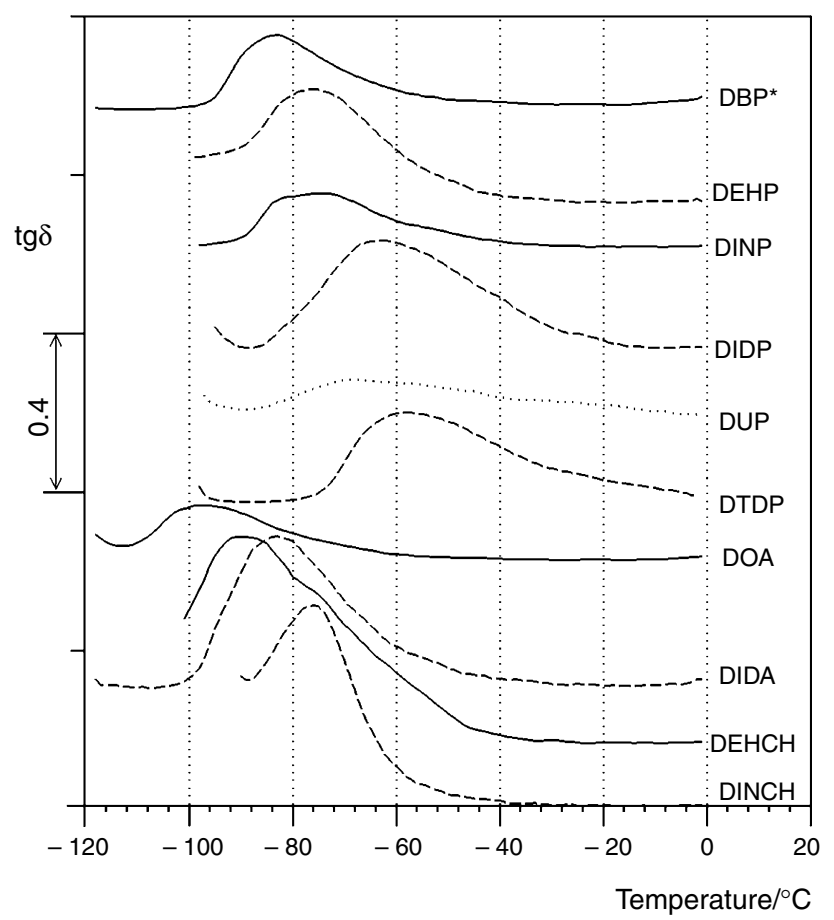

Fig. 4 DMA mechanical loss factor curves of plasticizers

Plotting the normalized TSD curves into groups: phthalates (Figs. 7, 8), adipates (Fig. 9) and cycloaliphatics (Fig. 10) compared to the DEHP shows well tendencies. Peak temperatures and relaxation strength values are plotted in Fig. 11. Two phthalates DINP and DUP show irregular behavior, lower peak temperature and lover relaxation strength. The DINP is a mixture of number of isomers [6], and it is supposed that DUP has similar mixture.

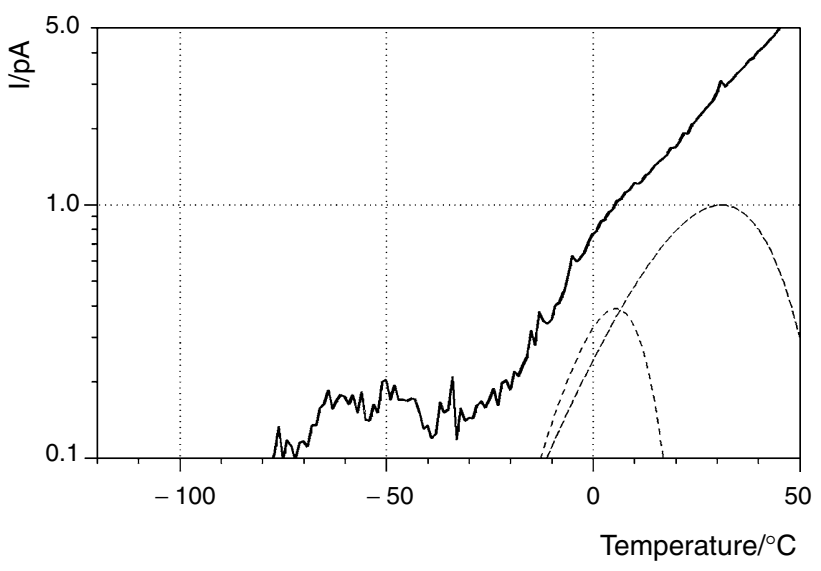

Fig. 5 Depolarization curve of borosilicate glass filter

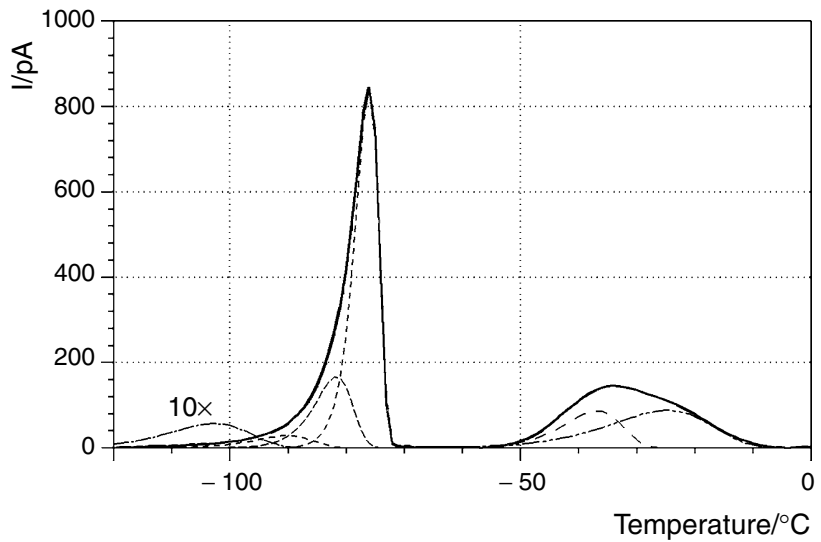

Fig. 6 Resolved TSD depolarization curve of diisodecyl phthalate 


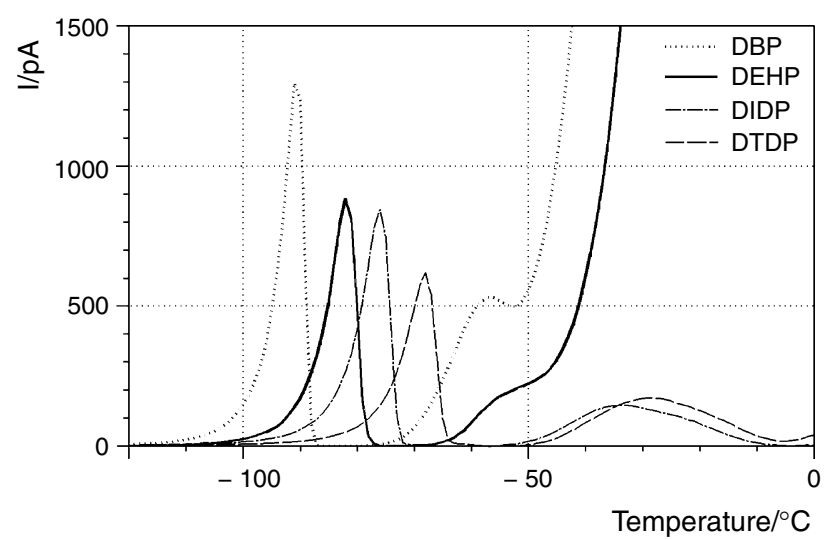

Fig. 7 TSD depolarization curves of phthalate plasticizers

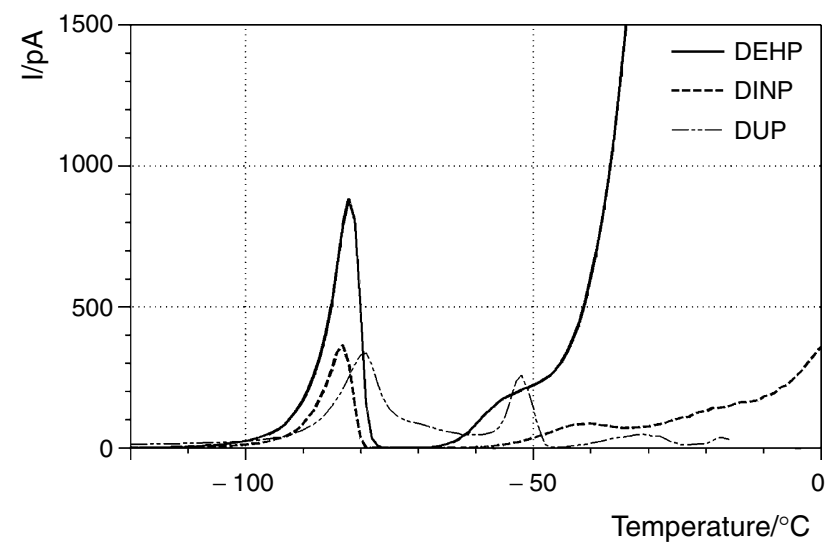

Fig. 8 TSD depolarization curves of irregular phthalate plasticizers (Solid line is DEHP for comparison)

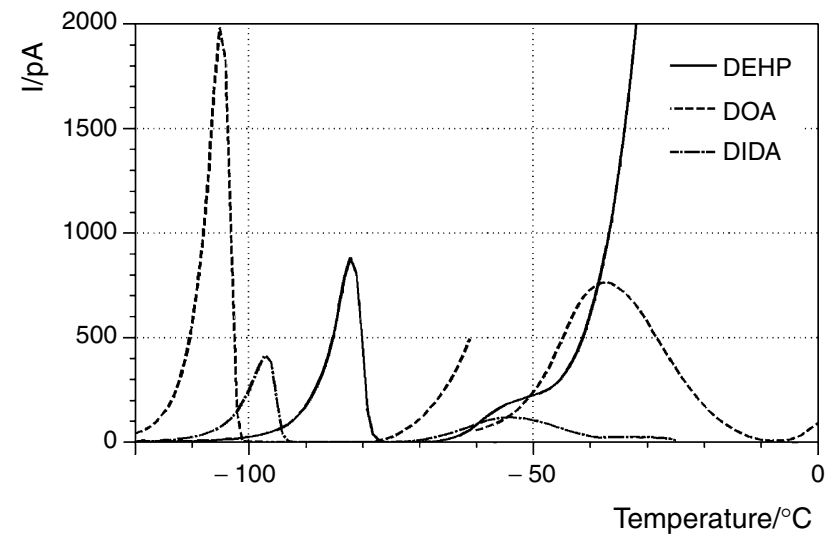

Fig. 9 TSD depolarization curves of adipate plasticizers. (Solid line is DEHP for comparison)

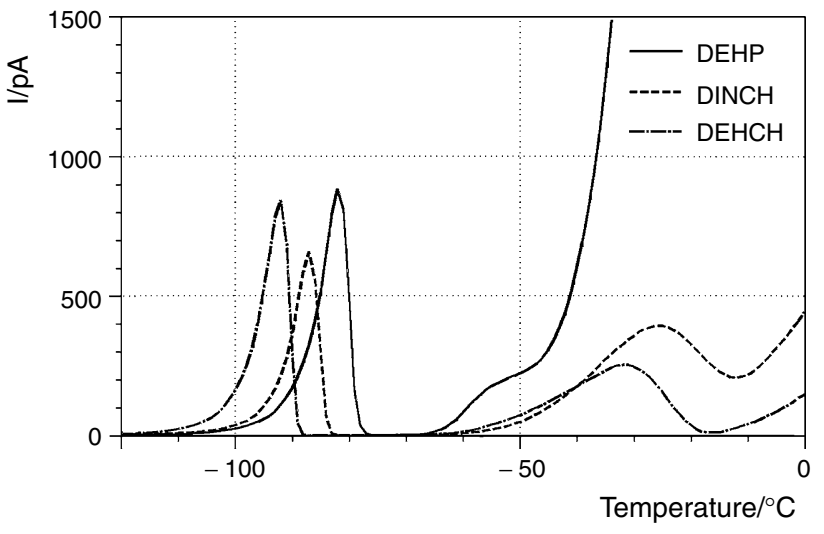

Fig. 10 TSD depolarization curves of cycloaliphatic plasticizers. (Solid line is DEHP for comparison)

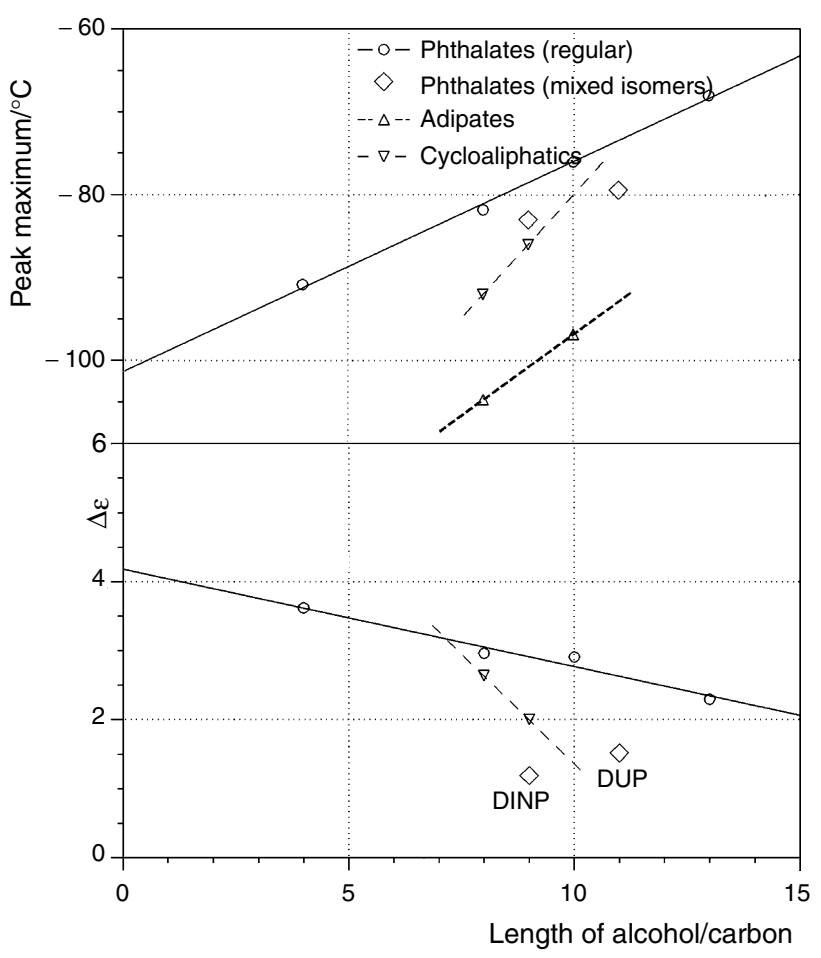

Fig. 11 Low temperature TSD peak position (above) and TSD peak relaxation strength (below) values of plasticizers. DUP and DINP $(\diamond)$ show irregular behavior 


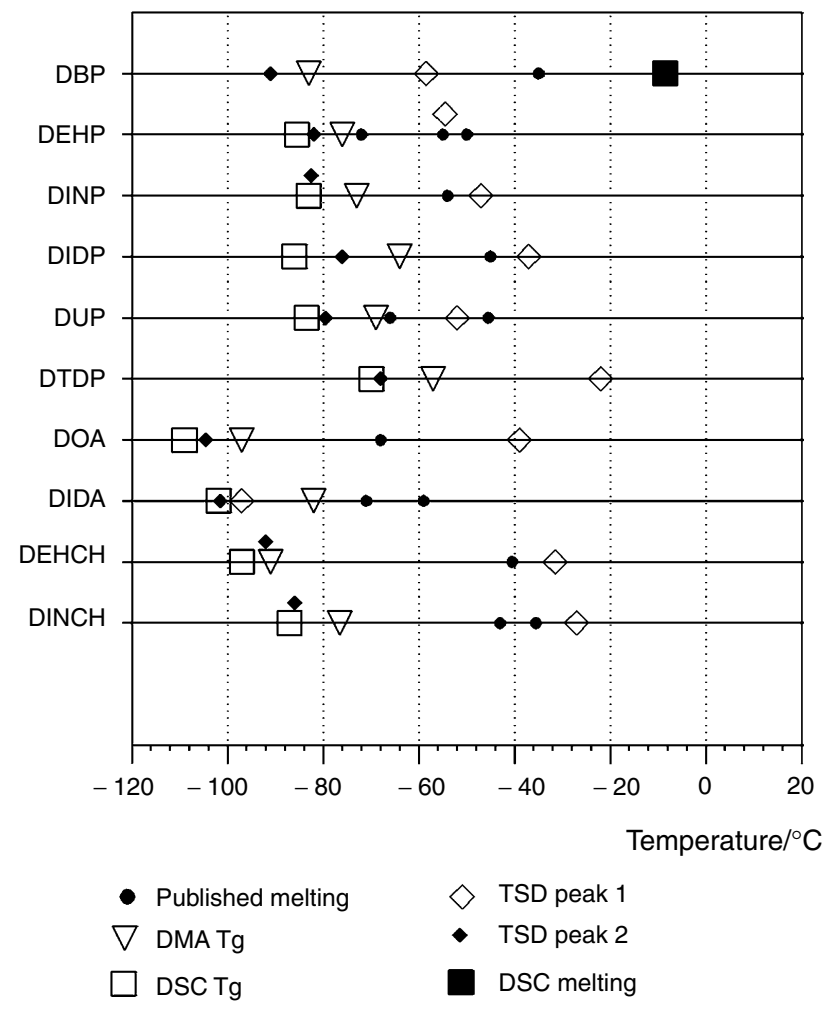

Fig. 12 Summarized test results compared to literature values

\section{Conclusions}

Both DMA and TSD proved to be a powerful method using the porous non-woven textile scaffolds. Neither cellulose in case of DMA nor borosilicate glass in case of TSD caused observable interaction processes; possibly these are below the detection limit. DSC is standard method for determination of melting temperature; regular melting process was observed in case of DBP only.

Measurement results are summarized in Fig. 12. There are very different published melting points sometimes near to one of our measurement results.

DSC measurements show "pseudo melting" at low temperature; these processes are rather glass transitions and were evaluated according to it. The only exception is DBP with regular crystalline melting. DBP has linear alkyl group without branching. All other plasticizers tested are esters of branched alcohols therefore might contain chiral carbon atoms. It hinders the crystallization, and the material is an amorphous glass at low temperature.

DMA also supports this conception. Surprisingly, DBP also has a transition at low temperature; these transitions arise from the movement of alkyl chains. The mobility decreases with the length of alkyl groups of alcohols, but the acid component also strongly affects the mobility. In terms of mobility, the order is adipates $>$ cycloalophatics $>$ phthalates. (In terms of temperature the order is reversed!) The two mixed alcohol phthalates show irregular behavior. $\operatorname{tg} \delta$ peak of DINP appears to be double while that of DUP is unusually broad. DMA method seems useful technique but scaffold of even higher pore volume would be better.

TSD is the most sensitive method for studying molecular motions. All plasticizers tested have two regions (dispersion ranges); these are complex. Resolving of the observed peaks was carried out (see Fig. 6), but the interpretation is not clear yet. Non-polar alkyl groups have unusual high relaxation strength caused by coupling to highly polar ester groups. TSD measurements also prove that the mobility of plasticizer alkyl groups is influenced by the acid; the order is the same as in case of DMA.

Because in case of mechanical method the forces are coupled, the probe size is larger than in case of electrical methods. Because of the extremely low effective frequency of TSD and the direct interaction with the exciting field, the probe size is smaller; the method is perceiving smaller region as independent part. By this way, the resolving power of TSD is much better than of DMA. It must be noted that TSD reveals processes, e.g., phase boundary interactions being not measurable by other methods. However, these processes complicate the evaluation.

There is no explanation what is the reason of serious differences between the published melting temperatures and results of recent study. However, one thing is certain; the published and data sheet values cannot be used without the information regarding the test methods.

Acknowledgements The research was carried out as part of the EFOP3.6.1-16-2016-00011 "Younger and Renewing University-Innovative Knowledge City-institutional development of the University of Miskolc aiming at intelligent specialization" project implemented in the framework of the Széchenyi 2020 program. The realization of this project is supported by the European Union, co-financed by the European Social Fund. The authors also acknowledge the Stipendium Hungaricum Scholarship, tempus Public foundation, and the Nigeria Federal Scholarship Board and also the BorsodChem Zrt for allowing the execution of part of this project at their laboratory.

Funding Open access funding provided by University of Miskolc.

Open Access This article is licensed under a Creative Commons Attribution 4.0 International License, which permits use, sharing, adaptation, distribution and reproduction in any medium or format, as long as you give appropriate credit to the original author(s) and the source, provide a link to the Creative Commons licence, and indicate if changes were made. The images or other third party material in this article are included in the article's Creative Commons licence, unless indicated otherwise in a credit line to the material. If material is not included in the article's Creative Commons licence and your intended use is not permitted by statutory regulation or exceeds the permitted use, you will need to obtain permission directly from the copyright holder. To view a copy of this licence, visit http://creativecommons.org/licenses/by/4.0/. 


\section{References}

1. Tseretely GI, Smirnova OI. DSC study of melting and glass transition in gelatins. J Therm Anal. 1992. https://doi.org/10.1007/ BF01979179.

2. Corriea NT, Alvarez C, Ramos JJM, Descamps M. Molecular motions in molecular glasses as studied by thermally stimulated depolarization currents (TSDC). Chem Phys. 2000;252:151-63.

3. Bansak N, Dhaliwal AS, Mann KS. Dielectric characterization of rapeseed (Brassica nalus L.) from 10 to $3000 \mathrm{MHz}$. Biosyst Eng. 2016;143:1-8. https://doi.org/10.1016/j.biosystems eng.2015.12.014.

4. Hedvig P. Dielectric Spectroscopy of Polymers. Bristol: Hilger; 1977.

5. Marossy K. Practical approach to thermally stimulated discharge (TSD) method on polymers. J Therm Anal Calorim. 2017;129(1):161-70. https://doi.org/10.1007/s10973-017-6098-6.

6. Tenczerné G, Zs-Marossy K. Ftalát lágyítók értékelése lágy PVC receptúrákban (Evaluation of phtalate plasticizers in PVC formulation). Stabinform. 1992;17:34-7.

7. https://en.wikipedia.org/wiki/Dibutyl_phthalate (Accessed on 04 Mar 2019)

8. Silver Fern Chemical, Inc. Dibutyl Phthalate, Safety Data Sheet, 29 March 2017.
9. Anna Wypych: Databook of Plasticizers; Elsevier, (2017) ISBN $1927885159,9781927885154$.

10. Eastman (TM) DOP Plasticizer; Safety Data Sheet Version 2.1 PRD Revision Date: 11/13/2018.

11. TENOIT CO.LTD. Taiwan; Di-Isononyl Phthalate(DINP) Material Safety data sheet (No data of issue).

12. Megaloid Laboratories, Diisodecyl Phthalate Safety Data Sheet April 2013.

13. https://www.chemicalbook.com/ProductChemicalProperties CB6135878_EN.htm (Accessed on 01 June 2019).

14. https://pubchem.ncbi.nlm.nih.gov/compound/ditridecyl_phtha late\#section=Top (Accessed on 11 Nov 2019).

15. Hanwha Chemical Co. Ltd. Korea, eco-DEHCH Technical Data Sheet, Issued: 7th March 2018.

16. BASF Hexamoll DINCH technical data sheet (April 2016).

17. Jayflex ${ }^{\mathrm{TM}}$ DIDP technical data sheet.

Publisher's Note Springer Nature remains neutral with regard to jurisdictional claims in published maps and institutional affiliations. 